\title{
Les Lieux de Pascal Quignard, sous la direction d'Agnès Cousin de Ravel, Chantal Lapeyre- Desmaison et Dominique Rabaté
}

\section{Stefano Genetti}

\section{(2) OpenEdition}

\section{Journals}

\section{Edizione digitale}

URL: http://journals.openedition.org/studifrancesi/1472

DOI: 10.4000/studifrancesi. 1472

ISSN: 2421-5856

\section{Editore}

Rosenberg \& Sellier

\section{Edizione cartacea}

Data di pubblicazione: 1 décembre 2015

Paginazione: 633-634

ISSN: 0039-2944

\section{Notizia bibliografica digitale}

Stefano Genetti, «Les Lieux de Pascal Quignard, sous la direction d'Agnès Cousin de Ravel, Chantal Lapeyre-Desmaison et Dominique Rabaté», Studi Francesi [Online], 177 (LIX | III) | 2015, online dal 01 décembre 2015, consultato il 11 février 2021. URL: http://journals.openedition.org/studifrancesi/1472 ; DOI: https://doi.org/10.4000/studifrancesi.1472

Questo documento è stato generato automaticamente il 11 février 2021.

\section{cc) (†)}

Studi Francesi è distribuita con Licenza Creative Commons Attribuzione - Non commerciale - Non opere derivate 4.0 Internazionale. 


\title{
Les Lieux de Pascal Quignard, sous la direction d'Agnès Cousin de Ravel, Chantal Lapeyre-Desmaison et Dominique Rabaté
}

\author{
Stefano Genetti
}

\section{NOTIZIA}

Les Lieux de Pascal Quignard, sous la direction d'Agnès COUSIN DE RAVEL, Chantal LAPEYREDESMAISON et Dominique RABATÉ, Paris, Gallimard, 2014 («Les cahiers de la NRF»), pp. 256.

1 A una mappatura dell'opera di Pascal Quignard, tra tracce di vissuto e cartografia immaginaria, concorrono gli Atti del convegno svoltosi presso l'Université du Havre il 29 e 30 aprile 2013: luoghi dell'esperienza e del sapere, luoghi geografici - Le Havre, certo (Sonia ANTON, Pascal Quignard et la géocritique du Havre, pp. 21-25), ma anche Parigi e Sens, Ischia e l'Oriente - e luoghi testuali, luoghi perduti e «lieux intercesseurs» (Chantal LAPEYRE-DESMAISON, Agnès COUSIN DE RAVEL, Préface, pp. 7-13: p. 8) si intersecano nelle tre sezioni che compongono il volume: «Ruines», «Mémoires» e «Sources».

A partire dalla tavola rotonda L'origine est-elle un lieu?, condotta da Dominique RABATÉ e cui ha partecipato anche l'autore (pp. 90-104; si vedano anche le Notes pour une table ronde à l'intention d'Agnès Cousin de Ravel di Jacques HENRIC, pp. 85-89), si diramano le riflessioni sulle immagini spazio-temporali ricorrenti in una scrittura radicata nella «détresse originaire» (a usare l'espressione è Pascal QUIGNARD, p. 98). In Variations sur le lieu perdu (pp. 105-118), Chantal LAPEYRE-DESMAISON interroga sulla scia di Foucault «l'essence même du lieu perdu, au cœur de toute expérience de l'espace» (p. 105): di utopie in eterotopie, si approda alla centralità del corpo come luogo. In À l'origine du vide. Réfractions du "Dernier Royaume" - l'insieme giunto con Mourir de penser (Grasset, 2014) al nono tomo - Yves oUALLET sonda, tra vanità e pienezza, le implicazioni fisiche, 
etiche ed estetiche dell'esperienza del vuoto (pp. 143-161). In merito a vari testi - il trattatello conclusivo della Leçon de musique in Guilherme MASSARA, Musique et origine (pp. 162-176), La Voix perdue e altri contes in Lea Vuong, Pascal Quignard et le non-lieu du conte (pp. 220-232) - e da angolazioni diverse - in riva all'acqua e nelle profondità marine si situano gli interventi di Arlette FARGE (L'eau, la voix et l'ailleurs, pp. 183-185), di Irène FENOGLIO (L'eau, le lien, pp. 186-207, sugli avantesti di Boutès pubblicati in Sur le désir de se jeter à l'eau) e di Sarah BARBEDETTE («Mais il y a la mer - et qui l'épuisera?». Sur "Les Solidarités mystérieuses", pp. 208-219, con un suggestivo parallelo orientaleggiante tra le descrizioni quignardiane della costa bretone e le stampe del pittore e incisore Henri Rivière) - si disegnano i movimentati contorni di una psicogeografia letteraria. I romanzeschi Noms de pays (à partir du "Salon du Wurtemberg") su cui proustianamente si sofferma Dominique RABATÉ (pp. 119-131), così come i toponimi germanici e le cadenze del tedesco (Agnès cousin DE RAVEL, L'Allemagne de Pascal Quignard. «L'appel pur» de la langue, pp.132-142), vi assumono un ruolo tanto rilevante quanto gli innumerevoli riferimenti storici e libreschi (Nathalie PIÉGAY-GROS, Les lieux de l'érudition, pp. 233-245).

3 Al confluire di spazio e tempo, di biografia e scrittura, di letterale e metaforico, si colloca il topos delle rovine, del quale Pascal QUIGNARD stesso sottolinea l'importanza nel suo Entretien con Philippe PINTORE (pp. 177-185). Dai resti di Pompei (Bénédicte GORRILLOT, Pompéi ou la rhétorique spatialisée de Pascal Quignard, pp.51-68, su Le Sexe et l'effroi) - al sisma di Fukuoka e alla crisi nucleare di Fukushima, di riva devastata in deriva della memoria si cementa il nesso che l'autore stabilisce tra la propria infanzia nell'immediato dopoguerra in un porto bombardato (Pierre LEPAPE, Pascal Quignard au Havre, pp. 29-34; Jean-Louis PAUTROT, Les havres de Pascal Quignard, pp.35-50) e l'occupazione americana alla quale sotterraneamente reagisce in Giappone la danza butoh incarnata da Carlotta Ikeda, al cui fianco Quignard ha portato in tournée, da Parigi a Tokyo, la sua Medea, l'ultima rappresentazione avendo avuto luogo proprio a Le Havre, a coronamento del presente convegno (Carlotta Ikeda è mancata il 24 settembre 2014). Ed è sul dispositivo teatrale di questa pièce che sfocia l'intensa meditazione di Mireille CALLE-GRUBER (Au commencement la ruine du commencement, pp. 69-84) sulla ferita come origine e sulla rovina come fondamento, da Sarx (1977) fino a L'Origine de la danse (2013). Le rovine della Storia sono le macerie dalle quali rinasce una scrittura infranta ed eterogenea, che veglia sui morti ed evoca fantasmi, ombre sottratte alla deportazione dell'oblio. È la spiaggia desolata, colma di detriti, sulla quale viene ricostruita la città "assente" dove l'autore è cresciuto, uno spazio urbano catalizzatore e generatore di immagini in cui Pascal Quignard riconosce una matrice della sua scrittura nel testo L'Estuaire, contenuto nel catalogo, a cura di Dominique ROUET, della mostra fotografica allestita per l'occasione (Pascal Quignard: une enfance harvaise, Nolléval, Éditions l'écho des vagues, 2013, pp. 6-11). 